\title{
Response to GH Treatment After Radiation Therapy Depends on Location of Irradiation
}

\author{
Susan R. Rose, ${ }^{1}$ Martin Carlsson, ${ }^{2}$ Adda Grimberg, ${ }^{3}$ Ferah Aydin, ${ }^{4}$ Assunta Albanese, ${ }^{5}$ \\ Anita C.S. Hokken-Koelega, 6,7 and Cecilia Camacho-Hubner ${ }^{2}$ \\ ${ }^{1}$ Pediatric Endocrinology and Metabolism, Cincinnati Children's Hospital Medical Center, University of \\ Cincinnati College of Medicine, Cincinnati, Ohio 45229; ${ }^{2}$ Pfizer Inc., Endocrine Care, New York, New York \\ 10017; ${ }^{3}$ Perelman School of Medicine, Univ. of Pennsylvania, Children's Hospital of Philadelphia, Philadelphia, \\ Pennsylvania 19104; ${ }^{4}$ Pfizer Health AB, Endocrine Care, Sollentuna, 19190, Sweden; ${ }^{5}$ St George's University \\ Hospitals NHS Foundation Trust, London SW17 OQT, UK; ${ }^{6}$ Dutch Growth Research Foundation, Rotterdam, \\ 3015GD, The Netherlands; and 7Erasmus University Medical Center, Sophia's Children's Hospital, Department \\ of Pediatrics, Division of Endocrinology, Rotterdam, 3015GD, The Netherlands
}

ORCiD numbers: 0000-0003-1328-1289 (S. R. Rose); 0000-0003-3106-0754 (M. Carlsson); 0000-0002-1523-1536 (A. Grimberg); 0000-0003-4051-6661 (A. Albanese).

Objectives: Cancer survivors with GH deficiency (GHD) receive GH therapy (GHT) after $1+$ year observation to ensure stable tumor status/resolution.

Hypothesis: Radiation therapy (RT) to brain, spine, or extremities alters growth response to GHT.

Aim: Identify differences in growth response to GHT according to type/location of RT.

Methods: The Pfizer International Growth Database was searched for cancer survivors on GHT for $\geq 5$ years. Patient data, grouped by tumor type, were analyzed for therapy (surgery, chemotherapy, RT of the focal central nervous system, cranial, craniospinal, or total body irradiation [TBI] as part of bone marrow transplantation), sex, peak stimulated GH, age at GHT start, and duration from RT to GHT start. Kruskal-Wallis test and quantile regression modeling were performed.

Results: Of 1149 GHD survivors on GHT for $\geq 5$ years (male 733; median age 8.4 years; GH peak $2.8 \mathrm{ng} / \mathrm{mL}$ ), 431 had craniopharyngioma (251, cranial RT), 224 medulloblastoma (craniospinal RT), 134 leukemia (72 TBI), and 360 other tumors. Median age differed by tumor group $(P<0.001)$. Five-year delta height SD score (SDS) (5-year $\triangle \mathrm{HtSDS}$; median [10th-90th percentile]) was greatest for craniopharyngioma, 1.6 (0.3-3.0); for medulloblastoma, 5-year $\Delta \mathrm{HtSDS} 0.9$ (0.0-1.9); for leukemia 5-year $\Delta \mathrm{HtSDS}$, after TBI $(0.3,0-0.7)$ versus without RT $(0.5,0-0.9)$, direct comparison $P<0.001$. Adverse events included 40 treatment-related, but none unexpected.

Conclusions: TBI for leukemia had significant impact on growth response to GHT.

Medulloblastoma survivors had intermediate GHT response, whereas craniopharyngioma cranial RT did not alter GHT response. Both craniospinal and epiphyseal irradiation negatively affect growth response to GH therapy compared with only cranial RT or no RT. (J Clin Endocrinol Metab 105: 1-12, 2020)

ISSN Print 0021-972X ISSN Online 1945-7197

Printed in USA

(c) Endocrine Society 2020.

This is an Open Access article distributed under the terms of the Creative Commons Attribution License (http://creativecommons.org/licenses/by/4.0/), which permits unrestricted reuse, distribution, and reproduction in any medium, provided the original work is properly cited.

Received 6 May 2020. Accepted 17 July 2020.

First Published Online 24 July 2020.

Corrected and Typeset 1 September 2020.
Abbreviations: BMI, body mass index; CNS, central nervous system; GHD, GH deficiency; GHT, GH therapy; KIGS, Pfizer International Growth Database; RT, radiation therapy; SAE, significant adverse event; SDS, SD score; TBI, total body irradiation. 
Key Words: growth hormone therapy, growth hormone deficiency, pediatric, cancer survivors, dose response, radiation therapy

$\mathbf{G}^{\prime}$ $\mathrm{H}$ deficiency is common after radiation therapy (RT) for treatment of childhood cancer (1-3). RT for childhood cancer may include cranial or craniospinal irradiation for brain tumor, nasopharyngeal tumor, orbital tumor, or central nervous system leukemia; or total body irradiation (TBI) as preparation for bone marrow transplantation. GH deficiency (GHD) is often the only pituitary hormone deficiency after low-dose cranial irradiation (18-24 Gy) $(4,5)$. Higher RT doses ( $\geq 30 \mathrm{~Gy}$ ) may lead to multiple pituitary hormone deficiencies (deficiencies of GH, TSH, ACTH, and gonadotropins) (5-15). Risk, severity, and timing of onset of GHD are affected by the RT dose to the hypothalamus, not the pituitary (16-19). The risk of GHD after irradiation also increases with age younger than 10 years at time of tumor treatment (20, 21). Precocious puberty or rapid progression of puberty can also occur after cranial RT $>18 \mathrm{~Gy}$, with female sex and younger age at initial RT being the most important risk factors (22).

Of note, recommendations for GH replacement for GHD (based on expert opinion) are to wait 1 year or longer after completion of cancer therapy with no tumor growth before initiating GH therapy to ensure stable status/ resolution of tumor $(3,23,24)$. GH treatment $(\mathrm{GHT})$ can be delayed longer depending on individual patient circumstances. GHT is considered safe in patients after central nervous system (CNS) tumors (25, 26 ) and is not associated with an increased risk of tumor recurrence or secondary tumors $(27,28)$. However, GHT should be considered only cautiously in persons with GHD after multiple recurrences, metastases, highly malignant tumors, or genetic predisposition to cancer $(29,30)$. Safety data have enabled earlier initiation of GHT to lengthen the duration of therapy. Suppression of precocious, early, or rapid puberty may additionally increase adult height (31-34).

Tumor therapies (chemotherapy, RT) may affect subsequent growth of the skeleton (35-37). For instance, TBI is known to disrupt the epiphyses and reduce height potential in cancer survivors (36-38). Several studies have shown poor growth after fractionated RT (cranial, craniospinal, TBI), regardless of whether children developed GHD (39-44). It appears that GHT for GHD after craniopharyngioma increases adult height (45). Because irradiation damages both the epiphyses and the bone matrix, the skeleton may not demonstrate the growth response to GHT that is expected in children with idiopathic GHD (46).
We hypothesized that RT to brain, spine, or extremities alters linear growth response to GHT. We sought to assess the relative effects on growth response to GHT of cranial irradiation versus craniospinal irradiation versus RT to all growth centers (as in TBI) in a large group of childhood cancer survivors. The aim was to identify differences in growth response to GHT according to type and location of RT. We also reviewed the occurrence of adverse events in these cancer survivors during GHT.

\section{Patients and Methods}

The Pfizer International Growth Database (KIGS) was searched for cancer survivors who had received GHT for at least 5 years. The 1149 cancer survivors were grouped by tumor type and data were analyzed for tumor therapy (surgery, chemotherapy, RT [focal CNS, whole brain, craniospinal, or TBI as part of bone marrow transplantation]), sex, peak stimulated GH level, age at GHT start, and duration from RT to GHT start. Details of imaging, specific chemotherapeutic agents, and irradiation dosimetry administered were not available in the database. Within tumor diagnosis, patients were grouped by presence or absence of RT (Table 1 ).

\begin{tabular}{|c|c|c|}
\hline Male & 733 & $64 \%$ \\
\hline Median age of GHT start (y) & 8.4 & $5.1,11.6$ \\
\hline Median peak GH (ng/mL) & 2.8 & $0.5,9.5$ \\
\hline Median duration GHT (y) & 7.5 & $5.5,11.0$ \\
\hline Median GH dose (mg/kg/wk) & 0.18 & $0.12,0.26$ \\
\hline \multicolumn{3}{|l|}{ Tumor groups } \\
\hline Craniopharyngioma total & 431 & $38 \%$ \\
\hline Cranial RT & 137 & $32 \%$ \\
\hline No RT & 268 & $62 \%$ \\
\hline Other/unknown & 26 & $6 \%$ \\
\hline Leukemia total & 134 & $12 \%$ \\
\hline TBI & 71 & $53 \%$ \\
\hline No TBI & 52 & $39 \%$ \\
\hline Other/unknown & 11 & $8 \%$ \\
\hline Medulloblastoma total & 224 & $19 \%$ \\
\hline Craniospinal RT & 189 & $84 \%$ \\
\hline Other/unknown & 35 & $16 \%$ \\
\hline Other tumor ${ }^{a}$ & 360 & $31 \%$ \\
\hline
\end{tabular}

Median and 10th, 90th percentiles are presented for continuous variables and Ns and \% are for categorical variables.

Abbreviations: GHT, GH therapy; RT, radiation therapy; TBI, total body irradiation.

"Other" tumor group and unknown RT groups are excluded from analysis.

${ }^{a}$ Other tumor diagnoses: germinoma (dysgerminoma, pinealoma) 65; tumor of the pituitary/hypothalamic area 50; astrocytoma 41; ependymoma 35; glioma 35, solid tumor 27; nasopharyngeal tumor 23; lymphoma other 7; Hamartoma 6; non-Hodgkin lymphoma 4; other cranial tumors 67. 
Children within each tumor group were categorized further as prepubertal versus pubertal at GHT start, based on testicular volume $>3 \mathrm{~mL}$ or Tanner stage for breast development $\geq 2$ as reported by the investigator to the KIGS database.

\section{Statistical Methods}

Height was expressed in SD score (SDS) units from the mean for age and sex (HtSDS). Likewise, change in height was expressed as delta $\mathrm{HtSDS}(\Delta \mathrm{HtSDS})$.

A stepwise regression model was used to identify covariates for inclusion in a quantile regression model of HtSDS at year 5 and $\triangle \mathrm{HtSDS}$ at years 1 and 5 as the dependent variables. The independent covariates were the background and start of GH variables listed in Table 2. Backwards stepwise variable selection was used with cutoff values of $P<0.05$ for entry and retention.

Quantile regression (47) was used to estimate the conditional median of height SDS at year 5 and $\Delta \mathrm{HtSDS}$ at years 1 and 5, including the significant covariates identified in the stepwise model (Table 3). The quantile regression technique was chosen for the analyses because of the non-normal distributions of the data as tested with the Shapiro-Wilk test, invalidating assumption for ordinary least-squares regression. Quantile regression allows estimation and inference related to the median without making any distributional assumptions, in contrast to least-squares methods that rely on a normality assumption. The skewness of the height SDS variables may reflect meaningful heterogeneity. Kruskal-Wallis test was applied to the continuous background and start of $\mathrm{GH}$ variables and $\chi^{2}$ test to the binary variables.

All statistical tests were carried out at the 2-sided significance level of $5 \%$. Statistical analyses were performed using SAS, version 9.4 (SAS Institute Inc., Cary, NC) using the QUANTREG procedure. The NPAR1WAY and FREQ procedures were applied for univariate testing of the background and start of GH variables presented in Table 2 .

\section{Results}

\section{Patient characteristics}

Of 1149 cancer survivors with GHD (male 733; median age 8.4 years; median $\mathrm{GH}$ peak $2.8 \mathrm{ng} / \mathrm{mL}$ ) treated with GH in KIGS, 431 had craniopharyngioma (251 with cranial RT), 224 had medulloblastoma (all with craniospinal RT), and 134 had leukemia (72 with TBI) (Tables 1 and 2). (The remaining survivors in each category did not receive any RT.) The other 360 patients were diagnosed with a variety of other tumors, which were treated with diverse regimens as clinically indicated for each of the different tumors. For clarity, given the diversity of their tumor therapies, their growth response to subsequent GHT was not included in this analysis. (A list of their diagnoses is shown as a footnote to Table 1.) No data were available in the database regarding adequacy of other hormone replacement (i.e., thyroid, hydrocortisone, vasopressin, or sex steroids).

Background characteristics according to tumor group are presented in Table 2 (top) including univariate testing of the variables. Table 2 (bottom) shows characteristics according to tumor group at start of GHT and at last reported clinic visit. In the quantile regression model, response to GHT within tumor groups was associated with HtSDS at 5 years after controlling for puberty status, age at tumor diagnosis, age at start of $\mathrm{GH}$, mid-parental height SDS, HtSDS at start of GH, body mass index (BMI) SDS at GHT start, and dose at GHT start (mg/kg/week).

\section{Height achieved during GHT according to tumor group}

Craniopharyngioma (RT) was associated with the tallest 5-year HtSDS (median 5-year HtSDS estimate $=-0.17)$ compared with the other tumor groups $(P<0.05)$, except for the craniopharyngioma (no RT) group (median estimate $=-0.23, P=\mathrm{NS}$ ). The median 5 -year HtSDS for the leukemia (TBI) was significantly lower than the other tumor groups (median estimate $=-1.74, P<0.05)($ Fig. 1$)$

Factors significantly associated with taller 5-year $\mathrm{HtSDS}$ included dose at start of GH, HtSDS at start of GH, mid-parental HtSDS, and BMI SDS at GH start. Age at tumor diagnosis and age at GH start were negatively associated with 5 -year HtSDS $(P<0.05)$. Results are displayed in Table 3 (top).

\section{Effects of initial pubertal status on HtSDS}

Overall, patients who were pubertal at start of GHT had a significantly taller 5 -year HtSDS compared with prepubertal patients, with an estimated difference of median 5 -year HtSDS effect equal to $0.45(P<0.0001)$ (Table 4 bottom, Fig. 2). This was in spite of the pubertal and prepubertal groups having a similar HtSDS at baseline. Results for each tumor group according to pubertal status at start of GHT are illustrated in Fig. 2. Interestingly, there was a significant interaction effect between tumor group and puberty status: patients in the prepubertal leukemia groups had a taller median 5 -year HtSDS compared with pubertal patients. An opposite effect was observed for the 3 other tumor groups in which prepubertal patients had a lower 5-year HtSDS than did the pubertal patients. The median age at GHT 


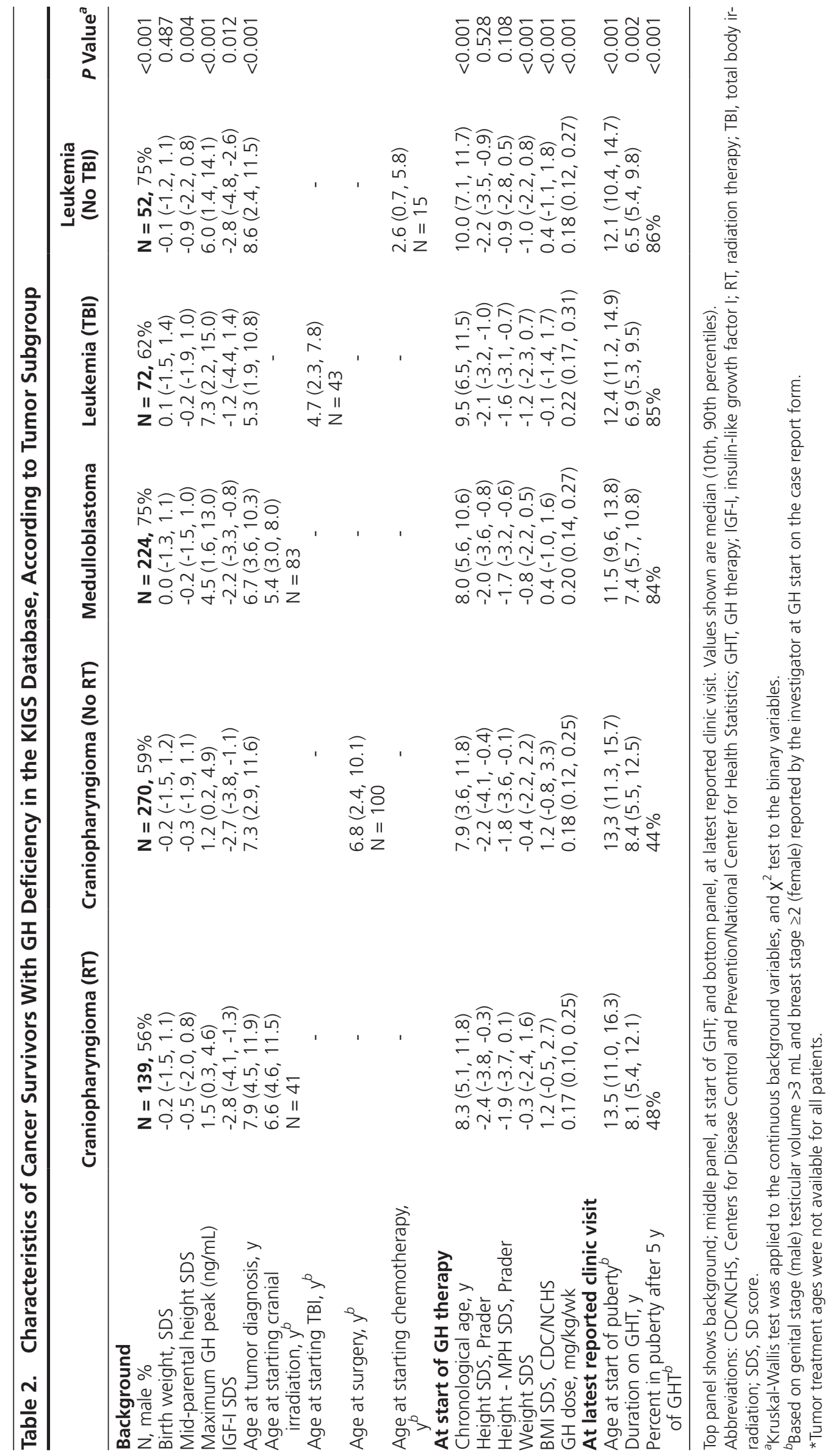




\begin{abstract}
Table 3. Quantile Regression of 1- and 5-Year Change in Height SDS ( $\Delta \mathrm{HtSDS}$ ) and Height in SD Units From the Mean for Age (HtSDS) at 5 Years of GH Therapy, for Childhood Cancer Survivors With and Without Irradiation in GH-Treated Cancer Survivors With GH Deficiency Entered in the KIGS Database, Quantile 0.50 (median)
\end{abstract}

\begin{tabular}{|c|c|c|c|c|c|c|}
\hline \multirow[b]{2}{*}{ Exploratory Variable } & \multicolumn{2}{|c|}{ 1-Year $\Delta$ HtSDS } & \multicolumn{2}{|c|}{ 5-Year $\Delta$ HtSDS } & \multicolumn{2}{|c|}{$\begin{array}{l}\text { HtSDS at } 5 \text { Years } \\
\text { of GH }\end{array}$} \\
\hline & Estimate & $P$ Value & Estimate & $P$ Value & Estimate & $P$ Value \\
\hline Craniopharyngioma (RT) & 0.75 & $<0.0001$ & 2.24 & $<0.0001$ & -0.17 & 0.47 \\
\hline Craniopharyngioma (no RT) & 0.80 & $<0.0001$ & 2.25 & $<0.0001$ & -0.23 & 0.32 \\
\hline Leukemia (TBI) & 0.27 & 0.015 & 0.90 & 0.0004 & -1.74 & $<0.001$ \\
\hline Leukemia (no TBI) & 0.50 & 0.0001 & 1.69 & $<0.0001$ & -0.77 & 0.002 \\
\hline Medulloblastoma & 0.47 & $<0.0001$ & 1.48 & $<0.0001$ & -1.02 & $<0.001$ \\
\hline $\begin{array}{l}\text { Craniopharyngioma RT } \\
\text { vs craniopharyngioma no RT }\end{array}$ & -0.05 & 0.47 & -0.01 & 0.96 & 0.05 & 0.68 \\
\hline Craniopharyngioma RT vs leukemia (TBI) & 0.48 & $<0.0001$ & 1.34 & $<0.0001$ & 1.56 & $<0.001$ \\
\hline Craniopharyngioma RT vs leukemia (no TBI) & 0.25 & 0.012 & 0.56 & 0.0004 & 0.59 & $<0.001$ \\
\hline Craniopharyngioma RT vs medulloblastoma & 0.28 & $<0.0001$ & 0.76 & $<0.0001$ & 0.85 & $<0.001$ \\
\hline Craniopharyngioma no RT vs leukemia (TBI) & 0.53 & $<0.0001$ & 1.35 & $<0.0001$ & 1.51 & $<0.001$ \\
\hline Craniopharyngioma no RT vs leukemia (no TBI) & 0.30 & 0.003 & 0.56 & 0.0004 & 0.54 & $<0.001$ \\
\hline Craniopharyngioma no RT vs medulloblastoma & 0.33 & $<0.0001$ & 0.76 & $<0.0001$ & 0.79 & $<0.001$ \\
\hline Leukemia (TBI) vs leukemia (no TBI) & -0.23 & 0.011 & -0.79 & $<0.0001$ & -0.97 & $<0.001$ \\
\hline Leukemia (TBI) vs medulloblastoma & -0.20 & $<.0001$ & -0.58 & $<0.0001$ & -0.72 & $<0.001$ \\
\hline Leukemia (no TBI) vs medulloblastoma & 0.03 & 0.72 & 0.21 & 0.15 & 0.25 & 0.018 \\
\hline In puberty & 0.57 & $<.0001$ & 1.84 & $<0.0001$ & -0.56 & 0.019 \\
\hline Prepubertal & 0.55 & $<.0001$ & 1.58 & $<0.0001$ & -1.01 & $<0.001$ \\
\hline In puberty vs prepubertal & 0.02 & 0.70 & 0.26 & 0.024 & 0.45 & $<0.001$ \\
\hline Age at GHT start (y) & -0.04 & 0.0003 & -0.07 & $<0.0001$ & -0.06 & 0.002 \\
\hline Weight (SDS) at GHT start & 0.04 & 0.003 & 0.07 & 0.39 & NA & \\
\hline Dose at GHT start (mg/kg/wk) & 1.56 & $<0.0001$ & 1.68 & 0.014 & 2.36 & $<0.001$ \\
\hline
\end{tabular}

Values shown are parameter estimates and $P$ values from quantile regression at the 50 th percentile.

Abbreviations: GHT, GH therapy; RT, radiotherapy; SDS, SD score; TBI, total body irradiation.

start for pubertal patients was 9.3 years versus 6.4 years for prepubertal patients, $P<0.001$.

\section{Change in HtSDS during GH therapy according to tumor group}

For the change in HtSDS ( $\Delta \mathrm{HtSDS})$ quantile regression models, response to GHT was significantly associated with tumor group and characteristics at GHT start (pubertal status, age, weight SDS, and initial GH dose).

One- and 5-year median changes in height SDS $(\Delta \mathrm{HtSDS})$ were greatest among tumor subgroups for craniopharyngioma, median (10th-90th percentile) 0.8 (0.1-1.5) and 1.6 (0.3-3.0), without cranial RT (1- and 5 -year values 0.8 [0-1.8], 1.6 [0.3-3.0]), and with cranial/focal RT (1- and 5-year values 0.7 [0.1-1.4], 1.5 [0.2-2.9], $P=$ NS) (Table 4 top). Delta HtSDS effects at 5 years of GHT for craniopharyngioma (RT) and (no RT) were associated with largest response to GHT (median 5-year $\Delta \mathrm{HtSDS}$ estimates 1.5, 1.6) compared with other tumor groups $(P<0.05)$ (Fig. 3).

For medulloblastoma, 1 - and 5 -year $\Delta \mathrm{HtSDS}$ were 0.5 (0.1-0.9) and 0.9 (0.0-1.9), respectively. This response was decreased compared with craniopharyngioma both with and without cranial RT (adjusted $P<0.0001$ ).
For leukemia, 1-year $\Delta \mathrm{HtSDS}$ after TBI was $0.3(0.0$ 0.7) compared with $0.5(0.0-0.9)$ for leukemia without RT, adjusted $P=0.011$. Five-year $\Delta \mathrm{HtSDS}$ after TBI was only 0.4 (-0.6 to 1.3$)$ compared with $1.0(0.2-1.9)$ for leukemia without RT (direct comparison adjusted $P<0.0001)$. These responses were decreased compared with craniopharyngioma at 1 and 5 years (adjusted $P<0.005$ ). The median $\Delta \mathrm{HtSDS}$ at 5 years for the leukemia (TBI) group was significantly less than for the other tumor groups (median 5 -year $\Delta \mathrm{HtSDS}$ estimate $=0.40, P<0.05)$. The comparisons of median $\Delta \mathrm{HtSDS}$ at 1 and 5 years in the leukemia (no TBI) versus medulloblastoma groups were not significant.

Pubertal patients had a greater 5-year $\triangle \mathrm{HtSDS}$ compared with prepubertal patients, with an estimated difference of median effects equal to $0.26(P<0.024)$.

As expected, given the shorter time duration, the median 1-year $\Delta \mathrm{HtSDS}$ effects were smaller compared with 5 years, with similar significant tumor group comparisons (Fig. 3). There was no significant effect of puberty on $\triangle \mathrm{HtSDS}$ at 1 year of GHT. Increased $\Delta \mathrm{HtSDS}$ was observed with higher weight SDS, median $\Delta \mathrm{HtSDS}$ equal to 0.04 . Dose at start of GHT was significantly associated with 1 -year $\Delta \mathrm{HtSDS}$. Older age at GH start was associated with significantly lower 


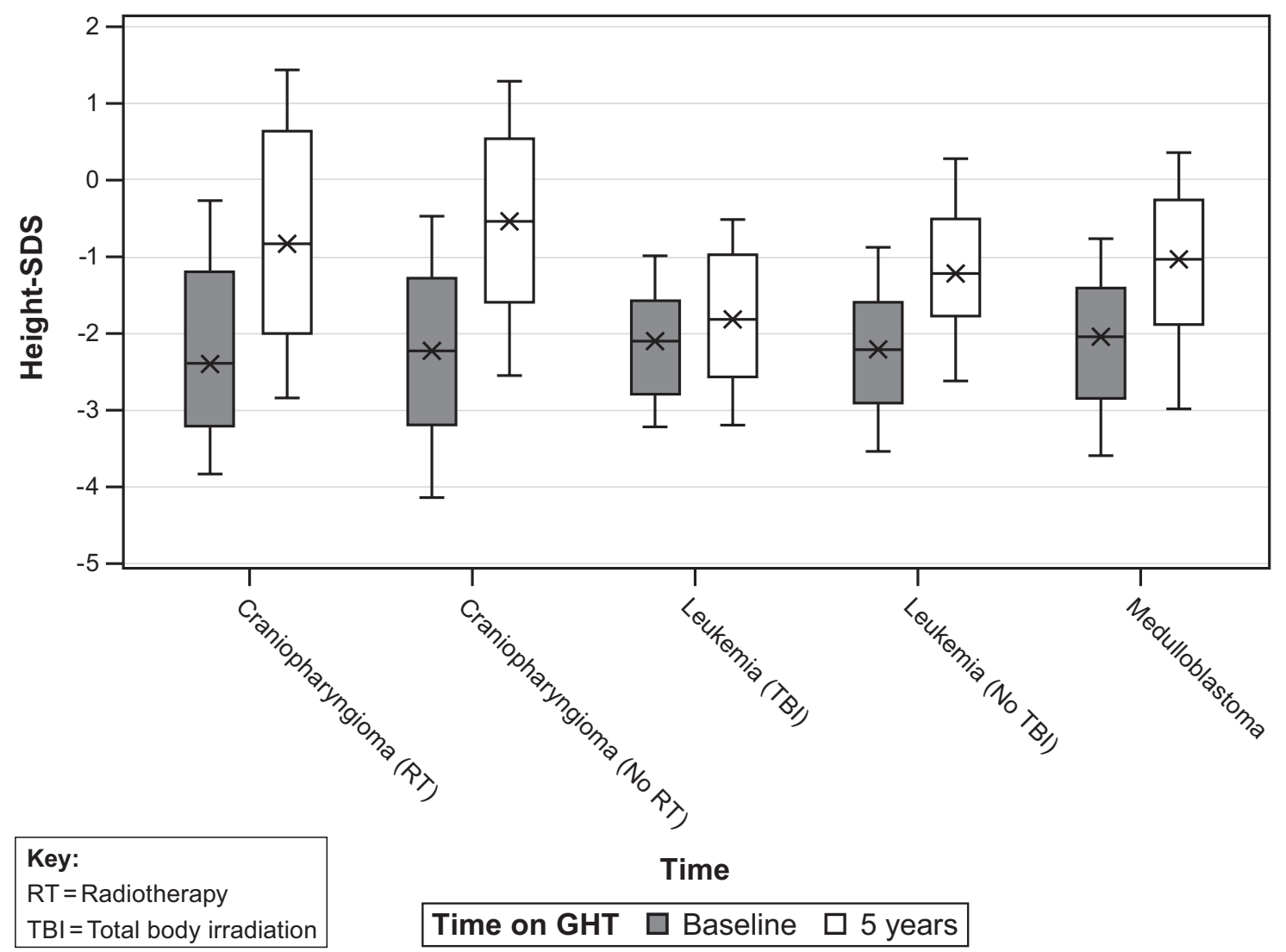

Figure 1. Height SD from the mean (HtSDS) at baseline before GH therapy (GHT) and after 5 years of GHT in GH-deficient childhood cancer survivors, according to tumor subgroup. SDS, SD score.

$\Delta \mathrm{HtSDS}$ of -0.04 for each 1-year increment in age at GH start. Results for $\triangle \mathrm{HtSDS}$ at years 1 and 5 are displayed in Table 4 (top).

Dose at start of GHT was significantly associated with an increased $\triangle \mathrm{HtSDS}$. Older age at GHT start was associated with a significantly lower $\Delta \mathrm{HtSDS}$ of -0.07 for each 1-year increment in age at GHT start.

\section{Growth for prepubertal cancer survivors (Table 4 bottom)}

One- and 5-years median HtSDS were greatest among tumor subgroups for craniopharyngioma, median (10th-90th percentile) $0.8(0.1-1.5)$ and $1.6(0.3-$ 3.0). For medulloblastoma, 1 - and 5 -year $\Delta \mathrm{HtSDS}$ were $0.5(-0.1$ to 0.8$)$ and $0.9(0.1-1.7)$, respectively. For leukemia, 1-year $\Delta \mathrm{HtSDS}$ after TBI was $0.3(0.0-0.7)$ compared with $0.5(0.0-0.9)$ for leukemia without RT. Five-year $\Delta \mathrm{HtSDS}$ after TBI 0.4 (-0.6 to 1.3 ) compared with $1.0(0.2-1.9)$ for leukemia without RT (direct comparison $P<0.05)$.

\section{Safety/adverse events}

There were no new serious adverse events (SAE) that have not been previously reported. Forty patients reported a treatment-related SAE (Table 5); none of the SAE were unexpected. Drug was withdrawn in 18 of the 40 patients who had treatment-related SAEs, mainly from those with craniopharyngioma recurrence. Dose was delayed in 9 while SAEs resolved. In the others, there was no change in GH therapy.

Overall, there were 1190 adverse events reported in 420 patients, with 325 considered as serious in 193 patients. Death was reported for 20 patients, of whom 4 deaths occurred after cessation of GHT (intracranial hemorrhage, suicide, T-cell lymphoma, and bone neoplasm) (Table 6).

\section{Treatment discontinuation}

Of the entire group of 1149 patients, 656 reported discontinuation of GHT. The most frequent explanations for discontinuation included completion of linear growth $(\mathrm{N}=341,52 \%)$, followed by poor height velocity $(154,23.5 \%)$, adverse event $(22,3.4 \%)$, lost to follow-up $(20,3.0 \%)$, and other reasons $(119,18.1 \%)$. The majority of patients who discontinued in the "other reasons" category withdrew for the following reasons: decision made by patient or parent $(\mathrm{N}=55)$, no funds for $\mathrm{GH}(\mathrm{N}=16)$, change of product $(\mathrm{N}=8)$, nonadherence $(\mathrm{N}=6)$, not responding to treatment $(\mathrm{N}=6)$, patient 
Table 4. Comparison of 1- and 5-Year Height in SDS from the Mean for Age (HtSDS) and Change in Height SDS ( $\triangle \mathrm{HtSDS}$ ) During GH Therapy, for Childhood Cancer Survivors With and Without Irradiation

\begin{tabular}{|c|c|c|c|c|}
\hline \multirow[b]{2}{*}{ Tumor Groups: All Patients } & \multicolumn{4}{|c|}{ Median Delta Height SDS (10th, 90th percentiles) } \\
\hline & $\begin{array}{l}\text { HtSDS at } \\
\text { Start of GH }\end{array}$ & 1-Year $\Delta$ HtSDS & 5-Year $\Delta$ HtSDS & $\begin{array}{c}\text { HtSDS at } \\
5 \text { Years of GH }\end{array}$ \\
\hline Craniopharyngioma (RT + no RT) & $\begin{array}{c}-2.3 \\
(-3.9,-0.4)\end{array}$ & $\begin{array}{c}0.8 \\
(0.1,1.5)\end{array}$ & $\begin{array}{c}1.6 \\
(0.3,3.0)\end{array}$ & $\begin{array}{c}-0.6 \\
(-2.6 .1 .4)\end{array}$ \\
\hline Leukemia (TBI) & $\begin{array}{l}-2.1 \\
(-3.2-1.0)\end{array}$ & $\begin{array}{c}0.3 \\
(0.0 .7)\end{array}$ & $\begin{array}{c}0.4 \\
(-0.61 .3)\end{array}$ & $\begin{array}{l}-1.8 \\
(-3.2-0.5)\end{array}$ \\
\hline Leukemia (no TBI) & $\begin{array}{c}-2.2 \\
(-3.5-0.9)\end{array}$ & 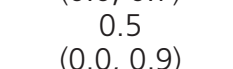 & $(021.0$ & $\begin{array}{c}-1.2 \\
(-26.03)\end{array}$ \\
\hline Medulloblastoma (craniospinal RT) & $\begin{array}{c}-2.0 \\
(-3.6,-0.8)\end{array}$ & $\begin{array}{c}0.5 \\
(0.1,0.9)\end{array}$ & $\begin{array}{c}0.9 \\
(0.0,1.9)\end{array}$ & $\begin{array}{c}-1.0 \\
(-3.0,0.4)\end{array}$ \\
\hline \multicolumn{5}{|l|}{ Tumor Groups: Prepubertal Patients } \\
\hline Craniopharyngioma (RT + no RT) & $\begin{array}{c}-2.5^{\mathrm{a}} \\
(-4.3,-0.7)\end{array}$ & $\begin{array}{c}0.8 \\
(0.1,1.7)\end{array}$ & $\begin{array}{c}1.6 \\
(0.3,3.3)\end{array}$ & $\begin{array}{c}-0.8^{\mathrm{a}} \\
(-2.9,1.4)\end{array}$ \\
\hline Leukemia (TBI) & $\begin{array}{l}-2.0 \\
(-32 .-12)\end{array}$ & $\begin{array}{c}0.3 \\
(0.0,0.9)\end{array}$ & $\begin{array}{c}0.4 \\
(0.0,1.7)\end{array}$ & $\begin{array}{c}-1.4 \\
(-2.7,-0.5)\end{array}$ \\
\hline Leukemia (no TBI) & $\begin{array}{c}-2.2 \\
(-3.2-1.6)\end{array}$ & $\begin{array}{c}0.5 \\
(0.1,0.9)\end{array}$ & $\begin{array}{c}1.1 \\
(-0.7,1.8)\end{array}$ & $\begin{array}{c}-1.1 \\
(-2.3,0)\end{array}$ \\
\hline Medulloblastoma (craniospinal RT) & $\begin{array}{c}-2.4 \\
(-4.0,-1.4)\end{array}$ & $\begin{array}{c}0.5 \\
(-0.1,0.8)\end{array}$ & $\begin{array}{c}0.9 \\
(0.1,1.7)\end{array}$ & $\begin{array}{c}-1.6 \\
(-3.5,-0.2)\end{array}$ \\
\hline
\end{tabular}

Top panel includes all patients; bottom panel includes only patients who were prepubertal at start of GHT. Abbreviations: RT, radiation therapy; TBI, total body irradiation; SDS, SD score.

${ }^{a}$ Data are presented as median delta height SD score (10th, 90th percentiles).

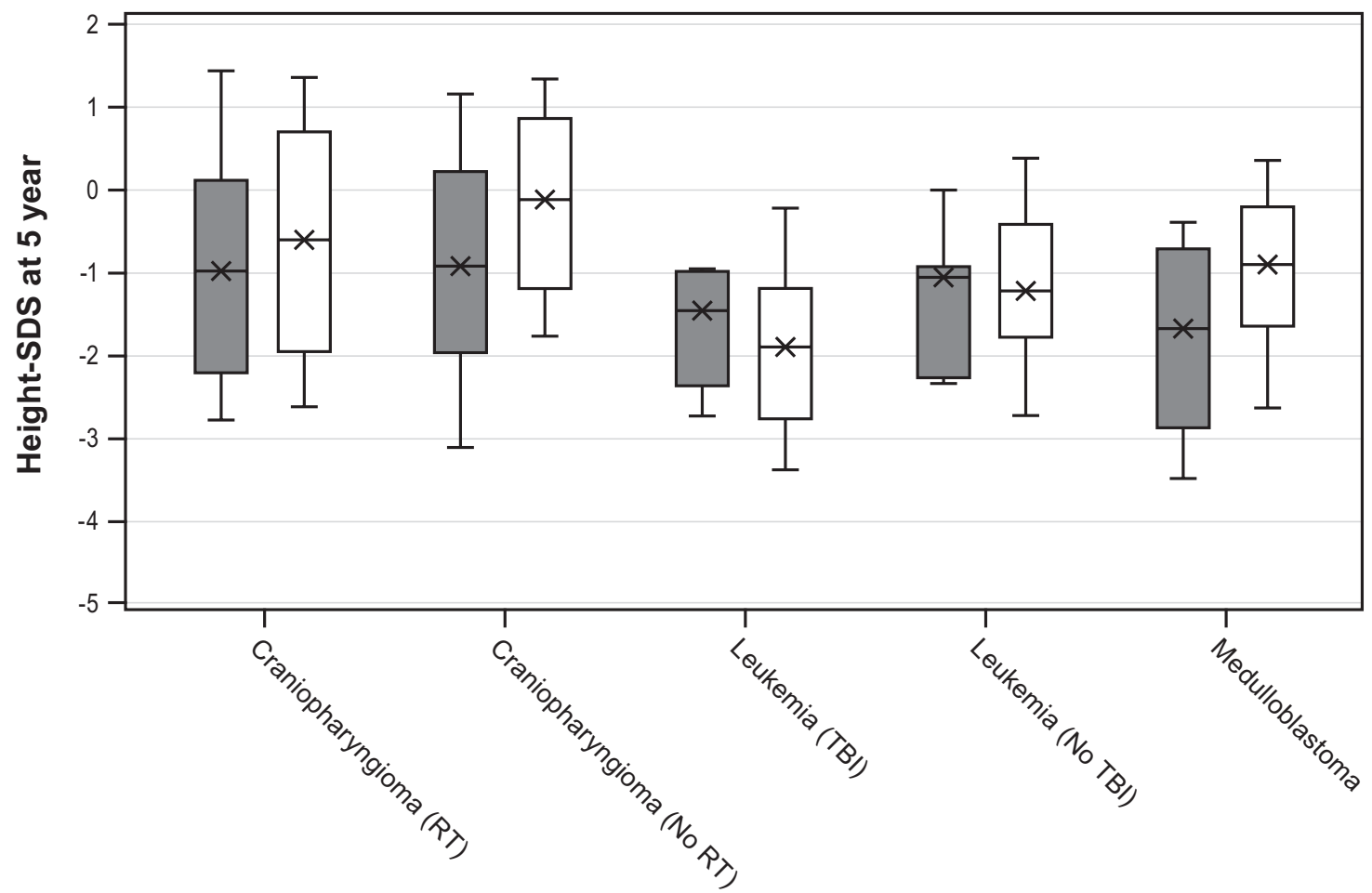

Key:

RT = Radiotherapy

$\mathrm{TBI}=$ Total body irradiation
Puberty Groups

\section{Puberty groups $\square$ prepubertal $\square$ pubertal}

Figure 2. Height SD from the mean (HtSDS) at 5 years of GH therapy (GHT) in prepubertal compared with pubertal GH-deficient childhood cancer survivors, according to tumor subgroup. SDS, SD score. 


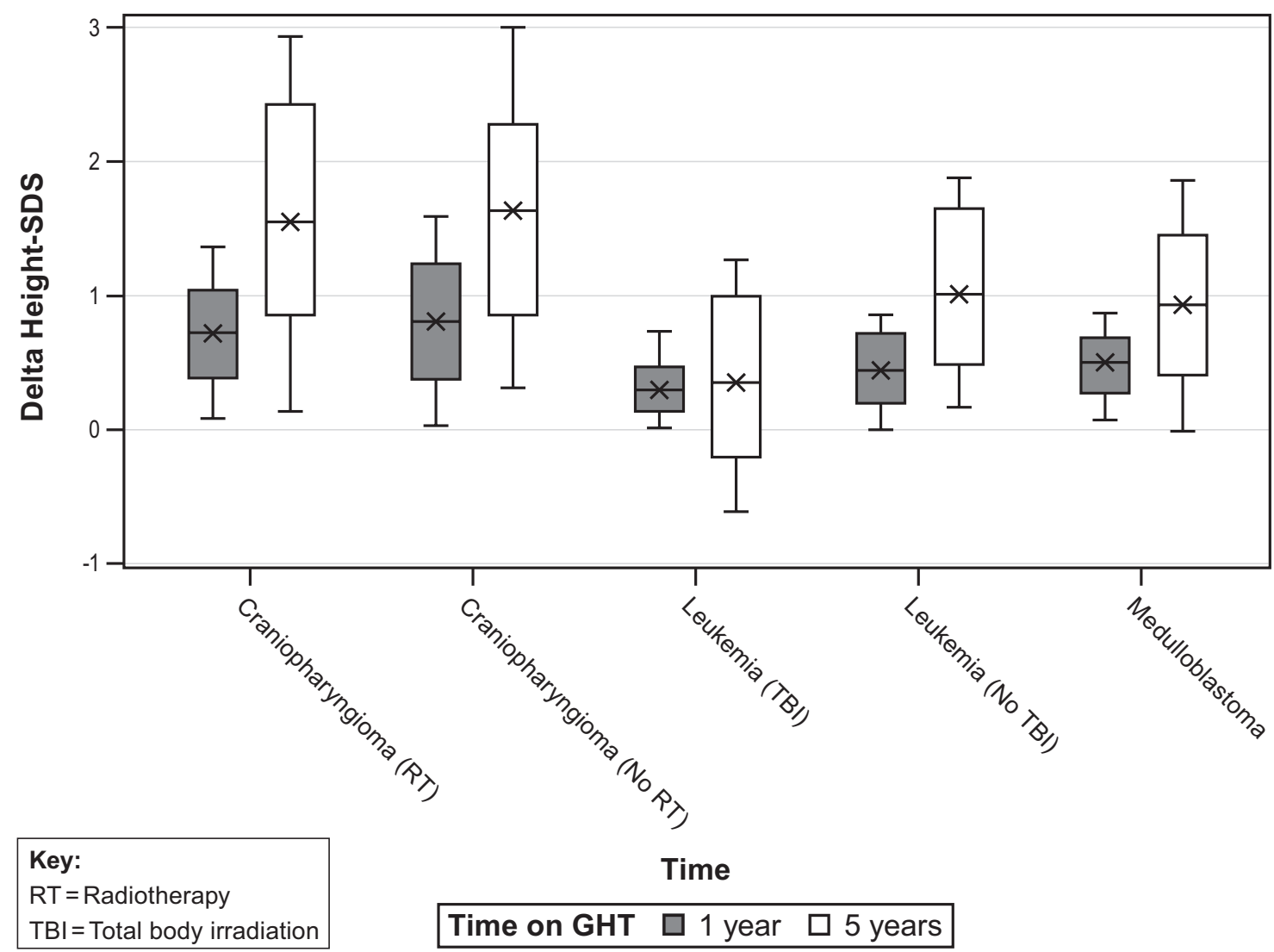

Figure 3. Change in height SD from mean baseline HtSDS ( $\triangle \mathrm{HtSDS}$ ) during GH therapy (GHT) in GH-deficient childhood cancer survivors at 1 and 5 years of GHT, according to tumor subgroup. SDS, SD score.

moved $(\mathrm{N}=5)$, study closure $(\mathrm{N}=3)$, treatment trial $(\mathrm{N}=2)$, closing center $(\mathrm{N}=2)$, change of diagnosis $(\mathrm{N}=1)$, and other unknown $(\mathrm{N}=15)$. The median duration of GHT at time of discontinuation for all reasons was 7.7 years, ranging from 6.4 years for adverse event to 8.2 years for near-adult height reached.

\section{Discussion}

The current study shows that at 1 and 5 years of GHT, leukemia survivors with GHD who had received TBI as part of preparation for bone marrow transplantation experienced the most significant impact of RT on their growth response to GHT compared with other tumor survivors with GHD. After medulloblastoma (typically treated with craniospinal RT), survivors had an intermediate growth response to GHT. After craniopharyngioma (treated either without RT or with cranial RT), survivors did not have reduced growth response to GHT. Thus, we observed that both craniospinal RT and general epiphyseal irradiation (TBI) were associated with restricted linear growth response during GH treatment for GHD compared with cranial RT only or no RT.

Several studies (that were smaller than the current one) have observed that vertebral growth slows after spinal irradiation or TBI, which are tumor therapies that contribute to short stature (35-37). Additional factors contributing to poor growth velocity in tumor survivors may include age at tumor therapy, hypothyroidism, sex, altered pubertal timing, GH insufficiency, secondary adrenal insufficiency, chronic unresolved illness, undernutrition, depression, and suppressive effects of chronic steroid therapy for graft-versus-host disease $(41,48)$. GH therapy after craniopharyngioma clearly increases adult height (45).

GHD in craniopharyngioma represents a probable direct effect of tumor burden as well as resulting from surgery in the hypothalamic-pituitary region. Many patients with craniopharyngioma demonstrated slowing of linear growth before any tumor therapy $(49,50)$. Tumor involvement of the hypothalamus may partially explain why the patient groups with craniopharyngioma receiving $\mathrm{RT}$ and without $\mathrm{RT}$ in the current study had similar baseline HtSDS and similar growth responses to GHT. GH therapy is often started in GHD craniopharyngioma survivors by 1 year after cranial surgery, before observing the effects of GHD on height.

In contrast, development of GHD after medulloblastoma or leukemia represents an effect of RT. In addition, start of GHT in GHD survivors of 
medulloblastoma or leukemia is usually delayed for more years after RT; thus, such patients may have significant growth deficit by the start of GHT.

Several studies have shown poor growth after fractionated RT (cranial, craniospinal, or TBI), regardless of whether children developed GHD (40-44). In addition, growth response to GHT is less after RT to epiphyseal growth centers (36). Irradiation damages both the epiphyses and the bony matrix; thus, the

Table 5. Treatment-Related Serious Adverse Effect Reported in $\mathbf{4 0}$ Cancer Survivors Treated With GH for GH Deficiency

\begin{tabular}{lll}
\hline Category & Diagnosis & $\begin{array}{l}\text { No. of } \\
\text { Pa- } \\
\text { tients }\end{array}$ \\
\hline $\begin{array}{c}\text { General and } \\
\text { metabolic }\end{array}$ & Fatigue & 1 \\
& Type 1 diabetes mellitus & 2 \\
Musculoskeletal & Mype 2 diabetes mellitus & 1 \\
& Muscle spasm & 1 \\
& Scoliosis & 3 \\
Nip epiphysiolysis & 1 \\
Tumor & Peripheral edema & 1 \\
& Headaches & 4 \\
& Epilepsy & 2 \\
& PNET progression & 1 \\
& Recurrence of & 20 \\
& craniopharyngioma & 1 \\
& Recurrence of Ewing & sarcoma \\
Recurrence of optic glioma & 3 (1 & death) \\
\hline
\end{tabular}

Abbreviation: PNET, primative neuroectodermal tumor. skeleton may not demonstrate the growth response to GHT that is expected in children with idiopathic GHD (46).

The observation that leukemia survivors with GHD who received no RT grew no better during GHT than medulloblastoma survivors (who had received craniospinal RT) suggests long-term effects on growth potential by other factors in leukemia therapy (such as steroids or chemotherapy). Several studies have observed absence of catch-up growth after completion of therapy in leukemia survivors who had received no RT. Lack of catch-up growth was associated with reduced adult height $(51,52)$. Specific causative factors were not identified; however, younger age at leukemia diagnosis and greater chemotherapy intensity were associated with shorter adult height (51). It is possible that GHT may not resolve all of the growth deficit in leukemia survivors.

It is unclear whether GHT can compensate for the effects of RT on epiphyseal growth. A comparison of cranial compared with craniospinal RT regarding growth response to GHT has been performed in small cohorts only (44, 53-57). In addition, comparisons within a common study have not been made of the effects of cranial and craniospinal RT to those of TBI on response to GHT, nor to the growth response to GH in children with idiopathic GHD without cancer history.

The strengths of the current analysis derive from the large number of patient observations in each tumor group and the at least 5 -year duration of observed GHT response. The study is limited by not having access in the database to details of imaging, tumor treatment details,

Table 6. Cause of Death in GH-Treated Cancer Survivors With GH deficiency, According to Tumor Group

\begin{tabular}{|c|c|c|c|c|c|c|}
\hline Primary Diagnosis & $\begin{array}{c}\mathrm{N} \\
\text { (male, } \\
\mathrm{N})\end{array}$ & $\begin{array}{l}\text { RT } \\
(\mathrm{N})\end{array}$ & $\begin{array}{c}\text { Age at GH } \\
\text { Start }(y)^{a}\end{array}$ & $\begin{array}{c}\text { GH Dose } \\
\text { (mg/kg/wk) }\end{array}$ & $\begin{array}{l}\text { Age at } \\
\text { SAE }(y)^{a}\end{array}$ & Cause of Death \\
\hline Medulloblastoma & $4(3)$ & $\begin{array}{l}1 \mathrm{C} \\
3 \mathrm{CS}\end{array}$ & $\begin{array}{c}7.7 \\
(3.9-8.8)\end{array}$ & $\begin{array}{c}0.12 \\
(0.05-0.19)\end{array}$ & $\begin{array}{c}15.0 \\
(11.6-16.8)\end{array}$ & $\begin{array}{l}\text { Tumor recurrence } \\
\text { Colorectal cancer } \\
\text { Pneumonia } \\
\text { Sudden collapse }\end{array}$ \\
\hline Others & $8(4)$ & $\begin{array}{l}4 \mathrm{C} \\
1 \mathrm{CS} \\
2 \mathrm{TBI} \\
1 \text { none }\end{array}$ & $\begin{array}{c}7.5 \\
(4.5-11.4)\end{array}$ & $\begin{array}{c}0.21 \\
(0.10-0.23)\end{array}$ & $\begin{array}{c}16.6 \\
(10.6-22.9)\end{array}$ & $\begin{array}{l}\text { Tumor recurrence }(n=2) \\
\text { Brain stem syndrome } \\
\text { Hepatocellular carcinoma } \\
\text { T-cell lymphoma } \\
\text { Myelodysplastic syndrome } \\
\text { Bone neoplasm } \\
\text { Epilepsy }\end{array}$ \\
\hline
\end{tabular}


body proportions such as sitting height measurements, details of timing of puberty, and other pituitary hormone dysfunction(s) and their treatment. These limitations are inherent in an analysis from a registry, where not all details from each patient were entered. Details about body proportions would be particularly useful in evaluating response to GHT in medulloblastoma patients who are treated with craniospinal RT.

It is likely that the growth response to GHT in cancer survivors with GHD could be associated with the RT dose to the hypothalamus or affected by additional factors not available in the database (precise pubertal timing, other hormone replacements, bone maturation).

Confounders in the analysis of the growth response to GHT are age and variation in the onset and tempo of puberty. Children who are younger at the onset of GHT have a faster initial growth velocity in response to GH than do those who are older at onset of GHT. In addition, timing of onset of puberty is often earlier after cranial RT, and rate of progression of puberty is often faster after cranial RT than in children without history of RT (33). These factors were not consistently reported in the KIGS database and could potentially affect our results. However, we did not observe less growth achieved over 5 years in our patients who received cranial RT compared with those without RT history.

Cancer survivors who were pubertal at the start of GHT generally reached a taller HtSDS after 5 years of GHT than did those who were prepubertal at start of GHT. Most likely, this was related to the pubertal growth spurt augmenting the growth response to GHT. Patients treated for leukemia with bone marrow transplantation with TBI were the exception. Their 5-year change in HtSDS was less than the prepubertal leukemia TBI group, perhaps because TBI (irradiation to all epiphyses) blunted the pubertal growth spurt.

Guidelines from the Endocrine Society, the Children's Oncology Group, and from transplant groups recommend that in childhood cancer survivors, monitoring (height, weight, BMI, and puberty) should be every 6 months until adult height is achieved, then yearly in individuals who are at risk of GHD (cranial irradiation $>18$ Gy) (3, 54, 58). Per Pediatric Endocrine Society guidelines, "For GH initiation after completion of tumor therapy with no evidence of ongoing tumor, a standard waiting period of 12 months to establish 'successful therapy' of the primary lesion is reasonable but can also be altered depending on individual patient circumstances" (23). Initial recommended dose of GHT in children with GHD is $0.16-0.24 \mathrm{mg} / \mathrm{kg}$ per week divided daily (22-35 $\mu \mathrm{g} / \mathrm{kg}$ per day), administered subcutaneously, with individualization of subsequent dosing $(23,25)$. The GH doses in the current report were generally near the lower end of this dose range. We suggest that GH doses be adjusted to achieve target IGF-I in the mid-normal range in cancer survivors (59), and that screening for additional endocrinopathies should be performed at least annually after RT (20). Adverse effects of GHT are rare, occur soon after therapy initiation, and include benign intracranial hypertension, slipped capital femoral epiphysis, scoliosis progression, or carpal tunnel syndrome (23). If coexisting ACTH deficiency is present, cortisol therapy should be started before $\mathrm{GH}$ or thyroid therapies.

Long-term surveillance is mandatory for childhood CNS tumor survivors treated with $\mathrm{GH}(3,23,25)$. It is important for clinicians to give patient-families realistic expectations of response to GHT so they can make appropriate, well-informed risk-benefit decisions (and also help prevent loss of adherence to GHT from disappointment that height is not increasing as anticipated). Those with a history of spinal RT should be prepared for suboptimal height increases as well as disproportionate elongation of legs relative to trunk. Otherwise, parents may request escalation of GHT doses, which still will not overcome RT effects but may increase risk for potential side effects. If families have appropriate expectations regarding limitations of GHT, hopefully there will be less pressure to pursue these strategies.

Clearly, GHT is effective in increasing growth achieved after tumor therapy in cancer survivors who have GHD. That less growth response is observed after leukemia with no RT, spinal RT, or TBI than in children without these treatments does not contravene use of GHT. Timing of onset and rate of progression of puberty may alter potential height gain. Use of GnRH analog therapy may prolong the cancer survivor's ability to respond to GHT (but may increase disproportion). The goal of GHT in these children is to assist cancer survivors in returning toward normal stature.

\section{Acknowledgments}

The authors express their thanks to all patients, parents, and KIGS investigators involved in providing data.

Financial Support: This study was sponsored by Pfizer Incorporated, New York City.

\section{Additional Information}

Correspondence and Reprint Requests: Susan R. Rose, MD, MLC 7012, Pediatric Endocrinology and Metabolism, Cincinnati Children's Hospital Medical Center, 3333 Burnet Avenue, Cincinnati, OH 45242. E-mail: mslrose4@gmail.com. 
Disclosure Summary: A.G. and A.H.-K. were members of the KIGS Steering Committee and received consultancy fees from Pfizer. A.G. was a consultant for the Pediatric Endocrine Society GHD Knowledge Center, sponsored by Sandoz. M.C. and C.C.-H. are full-time employees of Pfizer and F.A. was a full-time employee of Pfizer at the time of this study. S.R.R. and A.A. have no conflicts of interest to declare.

Data Availability: The datasets generated during and/or analyzed during the current study are not publicly available but are available from the corresponding author on reasonable request.

\section{References}

1. CureSearch Children's Oncology Group. Childhood Cancer Survivor Statistics. CureSearch Children's Oncology Group. www.curesearch.org/childhood-cancer-statistics. Accessed September 9, 2019.

2. Rose SR, Lawson S, Burns K, Merchant TE. Endocrine complications of cancer therapy. In: Schwartz CL, Hobbie WL, Constine LS, Ruccione KS, eds. Survivors of Childhood and Adolescent Cancer: A Multidisciplinary Approach. 3rd ed. Berlin: Springer-Verlag GmBH \& Co; 2015:65-94.

3. Sklar CA, Antal Z, Chemaitilly W, et al. Hypothalamic-pituitary and growth disorders in survivors of childhood cancer: an endocrine society clinical practice guideline. J Clin Endocrinol Metab. 2018;103(8):2761-2784.

4. Torino F, Barnabei A, Paragliola RM, Marchetti P, Salvatori R, Corsello SM. Endocrine side-effects of anti-cancer drugs: mAbs and pituitary dysfunction: clinical evidence and pathogenic hypotheses. Eur J Endocrinol. 2013;169(6):R153-R164.

5. Chemaitilly W, Sklar CA. Endocrine complications in long-term survivors of childhood cancers. Endocr Relat Cancer. 2010;17(3):R141-R159.

6. van Dijk IW, Cardous-Ubbink MC, van der Pal HJ, et al. Doseeffect relationships for adverse events after cranial radiation therapy in long-term childhood cancer survivors. Int J Radiat Oncol Biol Phys. 2013;85(3):768-775.

7. Wessel T, Balcerek M, Reinmuth S, et al. Age at menarche in childhood cancer survivors: results of a nationwide survey in Germany. Horm Res Paediatr. 2012;77(2):108-114.

8. Shalitin S, Gal M, Goshen Y, Cohen I, Yaniv I, Phillip M. Endocrine outcome in long-term survivors of childhood brain tumors. Horm Res Paediatr. 2011;76(2):113-122.

9. Rose SR, Danish RK, Kearney NS, et al. ACTH deficiency in childhood cancer survivors. Pediatr Blood Cancer. 2005;45(6):808-813.

10. Patterson BC, Truxillo L, Wasilewski-Masker K, Mertens AC, Meacham LR. Adrenal function testing in pediatric cancer survivors. Pediatr Blood Cancer. 2009;53(7):1302-1307.

11. Schwartz CL,Hobbie WL, Constine LS, Ruccione KS, eds. Survivors of Childhood and Adolescent Cancer: A Multidisciplinary Approach, 3rd ed. Berlin: Springer-Verlag GmBH \& Co; 2015:113 (algorithms), 151-166 (thyroid), 253-281 (gonads), 339-351 (transplantation), 369-384 (transition).

12. Ishida Y, Sakamoto N, Kamibeppu K, et al. Late effects and quality of life of childhood cancer survivors: part 2. Impact of radiotherapy. Int J Hematol. 2010;92(1):95-104.

13. Merchant TE, Goloubeva O, Pritchard DL, et al. Radiation dosevolume effects on growth hormone secretion. Int J Radiat Oncol Biol Phys. 2002;52(5):1264-1270.

14. Klose M, Jonsson B, Abs R, et al. From isolated GH deficiency to multiple pituitary hormone deficiency: an evolving continuum - a KIMS analysis. Eur J Endocrinol. 2009;161(Suppl 1):S75-S83.
15. Rose SR, Horne VE, Howell J, et al. Late endocrine effects of childhood cancer. Nat Rev Endocrinol. 2016;12(6):319-336.

16. Tulandi TGR, ed. Preservation of Fertility. London: Taylor and Francis; 2004:267.

17. Lam KS, Tse VK, Wang C, Yeung RT, Ho JH. Effects of cranial irradiation on hypothalamic-pituitary function-a 5-year longitudinal study in patients with nasopharyngeal carcinoma. Q J Med. 1991;78(286):165-176.

18. Felicetti F, Manicone R, Corrias A, et al. Endocrine late effects after total body irradiation in patients who received hematopoietic cell transplantation during childhood: a retrospective study from a single institution. I Cancer Res Clin Oncol. 2011;137(9):1343-1348.

19. Merchant TE, Rose SR, Bosley C, Wu S, Xiong X, Lustig RH. Growth hormone secretion after conformal radiation therapy in pediatric patients with localized brain tumors. J Clin Oncol. 2011;29(36):4776-4780.

20. Landier W, Skinner R, Wallace WH, et al. Surveillance for late effects in childhood cancer survivors. J Clin Oncol. 2018;36(21):2216-2222.

21. Landier W, ed. Long-Term Follow-up Guidelines for Survivors of Childhood, Adolescent, and Young Adult Cancers. Children's Oncology Group, version 5.0. (2019). www. survivorshipguidelines.org Accessed September 9, 2019.

22. Spoudeas H, Kirkham FJ. Toxicity and late effects. In: Walker D, Perilongo G Punt J, Taylor R, eds. Brain and Spinal Tumors of Childhood. Boca Raton, FL: CRC Press; 2004:443-462.

23. Grimberg A, DiVall SA, Polychronakos C, et al.; Drug and Therapeutics Committee and Ethics Committee of the Pediatric Endocrine Society. Guidelines for growth hormone and insulinlike growth factor-I treatment in children and adolescents: growth hormone deficiency, idiopathic short stature, and primary insulin-like growth factor-I deficiency. Horm Res Paediatr. 2016;86(6):361-397.

24. Raman S, Grimberg A, Waguespack SG, et al. Risk of neoplasia in pediatric patients receiving growth hormone therapy-a report from the pediatric endocrine society drug and therapeutics committee. J Clin Endocrinol Metab. 2015;100(6):2192-2203.

25. Ross RJ, Allen DB, Backeljauw P, et al. GH safety workshop position paper: a critical appraisal of recombinant human GH therapy in children and adults. Eur J Endocrinol. 2016;174(2):1-9.

26. Patterson BC, Chen Y, Sklar CA, et al. Growth hormone exposure as a risk factor for the development of subsequent neoplasms of the central nervous system: a report from the childhood cancer survivor study. J Clin Endocrinol Metab. 2014;99(6):2030-2037.

27. Darendeliler F, Karagiannis G, Wilton P, et al. Recurrence of brain tumours in patients treated with growth hormone: analysis of KIGS (Pfizer International Growth Database). Acta Paediatr. 2006;95(10):1284-1290.

28. Chung TT, Drake WM, Evanson J, et al. Tumour surveillance imaging in patients with extrapituitary tumours receiving growth hormone replacement. Clin Endocrinol (Oxf). 2005;63(3):274-279.

29. Juul A, Bernasconi S, Carel JC, Clayton PE, Kiess W, DeMuinckKeizer Schrama S; Drugs and Therapeutics Committee of the European Society for Paediatric Endocrinology. Growth hormone treatment and risk of solid tumours. a statement from the drugs and therapeutics committee of the European Society for Paediatric Endocrinology (ESPE). Horm Res. 2003;60(2):103-104

30. Molitch ME, Clemmons DR, Malozowski S, Merriam GR, Vance ML; Endocrine Society. Evaluation and treatment of adult growth hormone deficiency: an endocrine society clinical practice guideline. J Clin Endocrinol Metab. 2011;96(6):1587-1609.

31. Yanovski JA, Rose SR, Municchi G, et al. Treatment with a luteinizing hormone-releasing hormone agonist in adolescents with short stature. N Engl J Med. 2003;348(10):908-917. 
32. Oberfield SE, Soranno D, Nirenberg A, et al. Age at onset of puberty following high-dose central nervous system radiation therapy. Arch Pediatr Adolesc Med. 1996;150(6):589-592.

33. Armstrong GT, Whitton JA, Gajjar A, et al. Abnormal timing of menarche in survivors of central nervous system tumors: a report from the Childhood Cancer Survivor Study. Cancer. 2009;115(11):2562-2570.

34. Ogilvy-Stuart AL, Clayton PE, Shalet SM. Cranial irradiation and early puberty. J Clin Endocrinol Metab. 1994;78(6): 1282-1286.

35. Chen SH, Chen PQ, Huang TJ, Ko JY, Wang CJ. Surgical correction of postradiation spinal deformity. Chang Gung Med J. 2003;26(3):160-169.

36. Hovi L, Saarinen-Pihkala UM, Vettenranta K, Lipsanen M, Tapanainen P. Growth in children with poor-risk neuroblastoma after regimens with or without total body irradiation in preparation for autologous bone marrow transplantation. Bone Marrow Transplant. 1999;24(10):1131-1136.

37. Yu JI, Lim DH, Jung SH, Sung KW, Yoo SY, Nam H. The effects of radiation therapy on height and spine MRI characteristics in children with neuroblastoma. Radiother Oncol. 2015;114(3):384-388.

38. Probert JC, Parker BR. The effects of radiation therapy on bone growth. Radiology. 1975;114(1):155-162.

39. Shalet SM, Beardwell CG, Aarons BM, Pearson D, Jones PH. Growth impairment in children treated for brain tumours. Arch Dis Child. 1978;53(6):491-494.

40. Sanders JE, Pritchard S, Mahoney P, et al. Growth and development following marrow transplantation for leukemia. Blood. 1986;68(5):1129-1135.

41. Bakker B, Oostdijk W, Geskus RB, Stokvis-Brantsma WH, Vossen JM, Wit JM. Patterns of growth and body proportions after total-body irradiation and hematopoietic stem cell transplantation during childhood. Pediatr Res. 2006;59(2): 259-264.

42. Huma Z, Boulad F, Black P, Heller G, Sklar C. Growth in children after bone marrow transplantation for acute leukemia. Blood. 1995;86(2):819-824.

43. Brauner R, Rappaport R, Prevot C, et al. A prospective study of the development of growth hormone deficiency in children given cranial irradiation, and its relation to statural growth. $J$ Clin Endocrinol Metab. 1989;68(2):346-351.

44. Okońska M, Birkholz D, Korpal-Szczyrska M, AdamkiewiczDrozyńska E, Alska A, Magnuszewska H. [The evaluation of the influence of growth hormone therapy on growing process and metabolic functions in patients after treatment of craniopharyngioma.] Pediatr Endocrinol Diabetes Metab. 2010;16(1):19-24.

45. Buchinsky M. Recent advances in quantile regression models: a practical guideline for empirical research. J Hum Resour. 1998;33(1):88-126.

46. Papadimitriou A, Urena M, Hamill G, Stanhope R, Leiper AD. Growth hormone treatment of growth failure secondary to total body irradiation and bone marrow transplantation. Arch Dis Child. 1991;66(6):689-692.
47. Lerner SE, Huang GJ, McMahon D, Sklar CA, Oberfield SE. Growth hormone therapy in children after cranial/craniospinal radiation therapy: sexually dimorphic outcomes. J Clin Endocrinol Metab. 2004;89(12):6100-6104.

48. Ogilvy-Stuart AL, Shalet SM. Growth and puberty after growth hormone treatment after irradiation for brain tumours. Arch Dis Child. 1995;73(2):141-146.

49. Sorva R. Children with craniopharyngioma. Early growth failure and rapid postoperative weight gain. Acta Paediatr Scand. 1988;77(4):587-592.

50. Hoffmann A, Boekhoff S, Gebhardt U, et al. History before diagnosis in childhood craniopharyngioma: associations with initial presentation and long-term prognosis. Eur J Endocrinol. 2015;173(6):853-862.

51. Dalton VK, Rue M, Silverman LB, et al. Height and weight in children treated for acute lymphoblastic leukemia: relationship to CNS treatment. J Clin Oncol. 2003;21(15):2953-2960.

52. Bruzzi P, Predieri B, Corrias A, et al. Final height and body mass index in adult survivors of childhood acute lymphoblastic leukemia treated without cranial radiotherapy: a retrospective longitudinal multicenter Italian study. BMC Pediatr. 2014;14:236.

53. Clayton PE, Shalet SM, Price DA. Growth response to growth hormone therapy following cranial irradiation. Eur J Pediatr. 1988;147(6):593-596.

54. Sulmont V, Brauner R, Fontoura M, Rappaport R. Response to growth hormone treatment and final height after cranial or craniospinal irradiation. Acta Paediatr Scand. 1990;79(5):542-549.

55. Corrias A, Picco P, Einaudi S, et al. Growth hormone treatment in irradiated children with brain tumors. J Pediatr Endocrinol Metab. 1997;10(1):41-49.

56. Darendeliler F, Livesey EA, Hindmarsh PC, Brook CG. Growth and growth hormone secretion in children following treatment of brain tumours with radiotherapy. Acta Paediatr Scand. 1990;79(10):950-956.

57. Majhail NS, Rizzo JD, Lee SJ, et al.; Center for International Blood and Marrow Transplant Research (CIBMTR); American Society for Blood and Marrow Transplantation (ASBMT); European Group for Blood and Marrow Transplantation (EBMT); Asia-Pacific Blood and Marrow Transplantation Group (APBMT); Bone Marrow Transplant Society of Australia and New Zealand (BMTSANZ); East Mediterranean Blood and Marrow Transplantation Group (EMBMT), Sociedade Brasileira de Transplante de Medula Ossea (SBTMO). Recommended screening and preventive practices for long-term survivors after hematopoietic cell transplantation. Biol Blood Marrow Transplant. 2012;18(3):348-371.

58. Growth Hormone Research Society. Consensus guidelines for the diagnosis and treatment of growth hormone $(\mathrm{GH})$ deficiency in childhood and adolescence: summary statement of the GH Research Society. J Clin Endocrinol Metab. 2000;85(11):3990-3993.

59. Appelman-Dijkstra NM, Malgo F, Neelis KJ, Coremans I, Biermasz NR, Pereira AM. Pituitary dysfunction in adult patients after cranial irradiation for head and nasopharyngeal tumours. Radiother Oncol. 2014;113(1):102-107. 